\title{
Immunosuppressive effects of hydroxychloroquine and artemisinin combination therapy via the nuclear factor- $\kappa B$ signaling pathway in lupus nephritis mice
}

\author{
NING LIANG ${ }^{1,2^{*}}$, YANCHUN ZHONG $^{1 *}$, JIE ZHOU $^{1}$, BIHAO LIU $^{1}$, RUIRUI LU ${ }^{1}$, YEZHI GUAN $^{3}$,

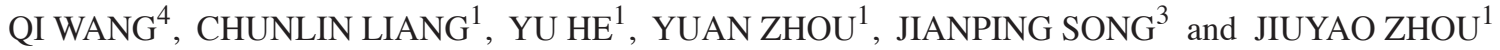

\begin{abstract}
${ }^{1}$ Department of Pharmacology, College of Chinese Materia Medica, Guangzhou University of Chinese Medicine, Guangzhou, Guangdong 510006; ${ }^{2}$ Department of Zhuang Medicine, College of Zhuang Medicine, Guangxi University of Chinese Medicine, Nanning, Guangxi 530001; ${ }^{3}$ Science and Technology Industrial Park, Guangzhou University of Chinese Medicine, Guangzhou, Guangdong 510445; ${ }^{4}$ Artepharm Co., Ltd., Guangzhou, Guangdong 510032, P.R. China
\end{abstract}

Received May 31, 2017; Accepted September 6, 2017

DOI: $10.3892 / \mathrm{etm} .2018 .5708$

\begin{abstract}
Lupus nephritis (LN) is one of the most common and severe manifestations of systemic lupus erythematosus, leading to permanent renal damage and chronic kidney disease. Hydroxychloroquine (HCQ) serves a protective role against lupus-associated clinical manifestations and medical complications; however, it results in numerous adverse reactions, limiting its long-term use. The aim of the present study was to investigate the combined effect of HCQ and artemisinin (ART) on LN, and to elucidate the underlying mechanisms. An in vivo LN mouse model was prepared, and the animals were administered prednisone (PDS; serving as a positive control), high-dose HCQ (H-HCQ) or low-dose HCQ combined with ART (L-HCQ + ART) once daily for 8 weeks. The body weight, serum biochemical parameters, immune and inflammatory indicators, renal and spleen histological alterations, and mRNA expression levels of Kruppel-like factor 15 (KLF15) and nuclear factor- $\kappa \mathrm{B}(\mathrm{NF}-\kappa \mathrm{B})$ were analyzed. It was observed that L-HCQ + ART and H-HCQ ameliorated the LN-induced body weight decrease, and significantly decreased the levels of anti-double stranded DNA, antinuclear antibodies, immunoglobulin $\mathrm{G}$, interferon $\gamma$, tumor necrosis factor- $\alpha$ and
\end{abstract}

Correspondence to: Dr Jianping Song, Science and Technology Industrial Park, Guangzhou University of Chinese Medicine, 436 Chen Tai Road, Guangzhou, Guangdong 510445, P.R. China E-mail: jianpingsongke@126.com

Dr Jiuyao Zhou, Department of Pharmacology, College of Chinese Materia Medica, Guangzhou University of Chinese Medicine, 232 East Ring Road, Guangzhou, Guangdong 510006, P.R. China E-mail: zhoujiuyao@tom.com

${ }^{*}$ Contributed equally

Key words: immunosuppressive effect, artemisinin, hydroxychloroquine, lupus nephritis transforming growth factor- $\beta 1$, as well as improved the kidney and spleen pathology, when compared with the model group. In addition, L-HCQ + ART and H-HCQ treatments induced KLF15 upregulation and $\mathrm{NF}-\kappa \mathrm{B}$ downregulation. These results indicated that treatment with L-HCQ + ART exerted renoprotective effects by regulating the expression levels of cytokines, KLF15 and NF- $\kappa \mathrm{B}$. This combination treatment may have a similar immunosuppressive effect as PDS and $\mathrm{H}-\mathrm{HCQ}$, and may be a promising alternative for $\mathrm{LN}$ treatment.

\section{Introduction}

Systemic lupus erythematosus (SLE) is a multisystem autoimmune disease with varying patterns of organ involvement. Lupus nephritis (LN) is a common and severe manifestation of SLE, and an important cause of acute kidney injury and end-stage renal disease (1). Immunosuppressive drugs, including cyclophosphamide and azathioprine, and adrenal hormones, such as prednisone (PDS), are clinical drugs used in the treatment of $\operatorname{LN}(2,3)$. However, these drugs present significant side effects with long-term and high-dose application. Therefore, alternative drugs and low-dose combination therapies have attracted increasing attention (4).

The multiple benefits of antimalarial therapy for lupus are currently widely recognized, including reducing damage, lowering the risk of developing nephritis and improving the outcome of nephritis treatment (5). Over the past decades, antimalarial drugs, most notably hydroxychloroquine (HCQ), have become a key part of SLE treatment strategies. HCQ is a lipophilic weak base that easily passes across cell membranes and into the acidic intracellular vesicles, including the lysosomes. Previous studies have indicated that HCQ may delay the onset of renal damage and improve the survival rates of patients with LN $(6,7)$. The HCQ immunomodulatory effects are mediated by its anti-inflammatory, immunosuppressive and photoprotective properties, and interfere with lysosomal degradation $(8,9)$. However, treatment with a high dose of HCQ may cause toxic retinopathy and induce toxic hepatitis (10-13). 
Artemisinin (ART), extracted from Artemisia annua L., is a novel type of sesquiterpene lactone compound that contains a hydroperoxyl radical group. A water-soluble ART derivative has been demonstrated to exert renoprotective effects, inhibit the proliferation and activation of B-cells, as well as reduce the generation of plasma cells in MRL/lpr mice (14). Furthermore, Wu et al (15) have observed that ART presented a therapeutic sensitization effect on glucocorticoid (GC) treatment in LN mice by increasing the expression levels of GC receptor $\alpha$ mRNA and the transcriptional coactivator P300/CREB-binding protein in renal tissues.

Based on previous studies, it is hypothesized herein that a combination of ART and a low dose of HCQ may have an immunosuppressive effect on LN. However, to the best of our knowledge there have been no previous studies on the effect of HCQ and ART combination treatment. In order to examine this hypothesis and identify the underlying mechanism, the present study investigated and compared the effects of treatment with a high dose of HCQ alone, as well as of treatment with a low dose of HCQ combined with ART in LN model mice. The effects on the body weight, biochemical serum parameters and mRNA expression levels of nuclear factor- $\kappa \mathrm{B}(\mathrm{NF}-\kappa \mathrm{B})$ pathway-associated enzymes were examined.

\section{Materials and methods}

Animals and reagents. A total of 50 Kunming (KM) female mice (weight, 18-22 g; age, 4 weeks; special pathogen-free; certificate no. SCXK 2013-0020) were obtained from the Laboratory Animal Services Centre of Guangzhou University of Chinese Medicine (Guangzhou, China). The animals were maintained on a 12-h light/12-h dark cycle under room temperature $\left(22 \pm 2^{\circ} \mathrm{C}\right)$ and humidity of $50 \pm 10 \%$, and fed with standard forage and clean water. The Guangzhou University of Chinese Medicine Science's Administrative Panel on Laboratory Animal Care approved all experimental procedures. All animal experiments were performed in accordance with institutional guidelines and ethics (16), and every effort was made to minimize animal suffering. HCQ was purchased from Zhejiang Kangle Pharmaceutical Co., Ltd. (Wenzhou, China), ART was supplied by Tongrentai Pharmaceutical Co., Ltd. (Sichuan, China), and PDS was purchased from the Second Affiliated Hospital, Guangzhou University of Chinese Medicine (Guangzhou, China).

Animal LN model and experimental groups. At 3 days prior to model establishment the splenic lymphocytes of KM mice were extracted by aseptic operation and immediately incubated at $37^{\circ} \mathrm{C}$ with $8 \mu \mathrm{g} / \mathrm{ml}$ concanavalin A (cat. no. C-2010; Sigma-Aldrich; Merck KGaA, Darmstadt, Germany) for $72 \mathrm{~h}$. The splenic lymphocytes of KM mice were subsequently adjusted to a concentration of $2 \times 10^{7} / \mathrm{ml}$ by 1640 complete medium and injected subcutaneously into each mouse once weekly for 4 weeks in order to establish the LN model, as previously described (17). The sham group was injected with normal saline, not spleen cells. At the beginning of week 5, 50 adult female Kunming mice were randomly divided into five groups as follows: Sham, model, PDS (10 mg/kg), high-dose HCQ (H-HCQ; $33.33 \mathrm{mg} / \mathrm{kg}$ ) and low-dose HCQ combined with ART (L-HCQ + ART; 16.6 and $5.55 \mathrm{mg} / \mathrm{kg}$, respectively) groups. There were 10 mice in each group. The mice were orally administered distilled water in the sham and model groups, or the corresponding treatment drugs in the PDS, H-HCQ and L-HCQ + ART groups, once daily for 8 weeks. The weights of the mice were measured once a week.

Blood, renal tissue and spleen tissue sample collection and preparation. Following 8 weeks of treatment the mice were anesthetized using ether (initial concentration, 10-15\%; maintenance, $3-5 \%$ ) in an anesthesia device and then sacrificed by cervical dislocation, blood was collected from the eyes. The serum was isolated by centrifugation at $2,000 \mathrm{xg}$ at $4{ }^{\circ} \mathrm{C}$ for $15 \mathrm{~min}$ for biochemical analysis. In addition, the kidneys and spleens of each rat were isolated and divided into two parts. One part of the tissue was fixed in $10 \%(\mathrm{v} / \mathrm{v})$ neutral formalin phosphate buffer for hematoxylin-eosin (HE) staining, while the remaining tissue was quickly frozen in liquid nitrogen and stored at $-80^{\circ} \mathrm{C}$ prior to use in quantitative polymerase chain reaction $(\mathrm{qPCR})$ analysis.

Biochemical analysis of serum parameters and urine. The day prior to the end of the experiment (prior to sacrifice), urine was collected using a urine collection device. The enzymatic activity of urine albumin(UALB) was detected using a Bradford Protein Assay kit (Beyotime Institute of Biotechnology, Haimen, China). In addition, ELISA kits were used to detect the concentrations of serum creatinine (SCr; AD2561Mo), urea nitrogen (BUN; AD1254Mo), anti-double stranded DNA (anti-ds-DNA; AD3384Mo), antinuclear antibodies (ANA; AD1565Mo), immunoglobulin G (IgG; AD2864Mo), interferon $\gamma$ (IFN- $\gamma$; AD3373Mo), tumor necrosis factor- $\alpha$ (TNF- $\alpha$; AD3051Mo) and transforming growth factor $\beta 1$ (TGF- $\beta 1$; AD2732Mo) (all Beijing Andy Huatai Technology Company, Ltd., Beijing, China). The kits were used according to the manufacturer's protocol.

RT-qPCR for Kruppel-like factor 15 (KLF15) and NF- $\kappa B$ $m R N A$ expression. The expression levels of KLF15 and $\mathrm{NF}-\kappa \mathrm{B}$ were determined in the renal tissue samples. The total RNA was extracted by using TRIzol reagent (Invitrogen; Thermo Fisher Scientific, Inc., Waltham, MA, USA), the concentration of total RNA was measured by microultraviolet spectrophotometer and $1.5 \mu \mathrm{g}$ of total RNA was used for cDNA reverse transcription (at $37^{\circ} \mathrm{C}$ for $15 \mathrm{~min}$ ) using a Reverse Transcriptase kit (D2639A; Takara Biotechnology Co., Ltd., Dalian, China). The total reaction mixture was $20 \mu 1$, made up of $10 \mu \mathrm{l}$ SYBR Premix Ex $\mathrm{Taq}^{\mathrm{TM}}$ II X2 (cat. no. RR420A; Takara Biotechnology Co., Ltd.), $0.8 \mu 1$ PCR forward primer $(10 \mu \mathrm{M}), 0.8 \mu \mathrm{l}$ PCR reverse primer $(10 \mu \mathrm{M}), 0.4 \mu \mathrm{l}$ ROX reference dye II X50, $6 \mu \mathrm{l} \mathrm{UdH}_{2} \mathrm{O}$ and $2 \mu \mathrm{l}$ cDNA. The RT-qPCR cycling program was set at one cycle of pre-denaturation at $95^{\circ} \mathrm{C}$ for $30 \mathrm{sec}$, followed by 40 cycles at $95^{\circ} \mathrm{C}$ for $5 \mathrm{sec}, 60^{\circ} \mathrm{C}$ for $34 \mathrm{sec}, 95^{\circ} \mathrm{C}$ for $15 \mathrm{sec}$, $60^{\circ} \mathrm{C}$ for $60 \mathrm{sec}$ and $95^{\circ} \mathrm{C}$ for $15 \mathrm{sec}$. The primer sequences were designed with the Primer Premier version 5.0 software (Premier Biosoft International, Palo Alto, CA, USA), and are presented in Table I. The relative levels of KLF15 and NF- $\kappa \mathrm{B}$ mRNA were normalized to the $\beta$-actin levels, and calculated using the $2^{-\Delta \Delta \mathrm{Cq}}$ formula (18). 
Table I. Sequences of the primers used in polymerase chain reaction.

\begin{tabular}{lllc}
\hline Genes & \multicolumn{1}{c}{ Sense primers $\left(5^{\prime} \rightarrow 3^{\prime}\right)$} & \multicolumn{1}{c}{ Antisense primers $\left(5^{\prime} \rightarrow 3^{\prime}\right)$} & Product $(\mathrm{bp})$ \\
\hline KLF15 & GTATGACCCAGAGCCACCAT & GAAGGCACAAAGGCACAAG & 20 \\
NF- $\mathrm{kB}$ & TCAATGGCTACACAGGACCA & CGCTTCTTCACACACTGGAT & 19 \\
$\beta$-actin & TGGAATCCTGTGGCATCCATGAAAC & TAAAACGCAGCTCAGTAACAGTCCG & 26 \\
\hline
\end{tabular}

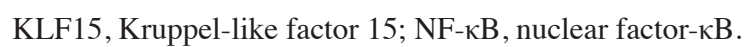

Western blot analysis of KLF15 and NF- $\mathrm{B} B$ protein expression levels. The kidney tissue samples were lysed using radioimmunoprecipitation lysis buffer (Beyotime Institute of Biotechnology) and the total protein concentrations were detected using the Micro BCA protein assay kit (Guangzhou Youdi Biotechnology Company, Guangzhou, China). Total cell lysates $(50 \mu \mathrm{g})$ were loaded into each lane and resolved by $12 \%$ sodium dodecyl sulfate-polyacrylamide gel electrophoresis, and then transferred to PVDF membranes (Thermo Fisher Scientific, Inc.). The PVDF membranes were blocked with $5 \%$ non-fat dry milk at room temperature for $1 \mathrm{~h}$ and immunoblotted with anti-KLF15 (ab2647; dilution 1:200) and anti-NF- $\mathrm{kB}(\mathrm{ab} 32360$; dilution $1: 1,000)$ at $37^{\circ} \mathrm{C}$ for $2 \mathrm{~h}$, followed by incubation with the secondary antibodies (ab6789; dilution 1:5,000) for another $1 \mathrm{~h}$ at room temperature. All antibodies were purchased from Abcam (Cambridge, MA, USA) Visualization was then performed using an enhanced chemiluminescence western blotting detection reagent (Thermo Fisher Scientific, Inc.). Finally, the protein bands were scanned and quantified using a ChemiDoc ${ }^{\mathrm{TM}}$ MP Imaging system (Bio-Rad Laboratories, Inc., Hercules, CA, USA).

HE staining of renal and spleen tissues. The renal and spleen tissue samples were fixed in $10 \%(\mathrm{v} / \mathrm{v})$ neutral formalin phosphate buffer, dehydrated in a graded series of alcohol and embedded in paraffin. Next, $5-\mu \mathrm{m}$ sections were stained with hematoxylin for $3 \mathrm{~min}$, washed and then stained with $0.5 \%$ eosin for a further $3 \mathrm{~min}$. The morphological alterations in the kidney and spleen were blindly evaluated under a light microscope (Nikon Eclipse TE2000; Nikon Corporation, Tokyo, Japan) by an experienced pathologist.

Statistical analysis. All data are presented as the mean \pm standard deviation. The values obtained in the same group prior to and following drug administration were compared using a paired t-test. Comparisons between groups were conducted using one-way analysis of variance followed by Duncan's test. $\mathrm{P}<0.05$ was considered to indicate a difference that was statistically significant.

\section{Results}

Body weight, UALB and serum biochemical parameters. As shown in Fig. 1, the body weight of LN animals was significantly decreased compared with the sham group $(\mathrm{P}<0.01)$. However, after 5 weeks, treatment in the PDS, H-HCQ and L-HCQ + ART groups helped to stabilize the body weight, and these animals presented a significantly higher weight

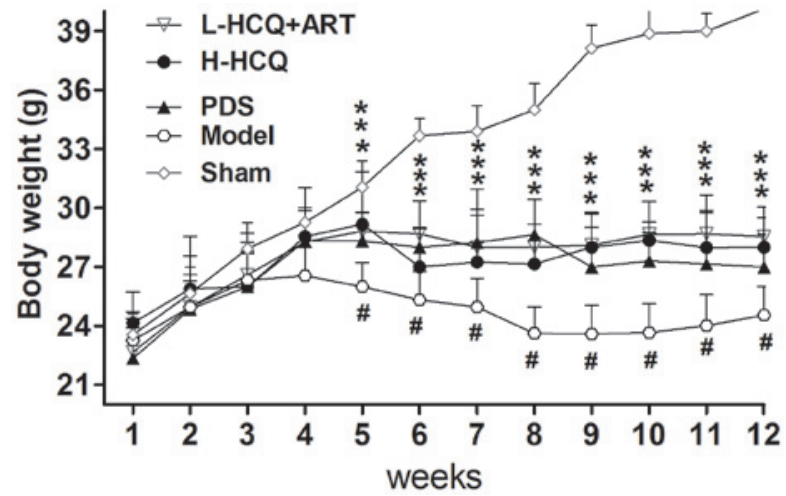

Figure 1. Body weights of mice in each group. ${ }^{*} \mathrm{P}<0.01$ vs. the sham group and ${ }^{* * * *} \mathrm{P}<0.05$ vs. the model group. PDS, prednisone; H-HCQ, high-dose hydroxychloroquine; L-HCQ, low-dose hydroxychloroquine; ART, artemisinin.

compared with the model group $(\mathrm{P}<0.05)$. Furthermore, the $\mathrm{L}-\mathrm{HCQ}+\mathrm{ART}$ treatment significantly reduced the $\mathrm{LN}$-induced UALB, SCr and BUN levels, as compared with the model group $(\mathrm{P}<0.05)$, which was similar to the effect of PDS and $\mathrm{H}-\mathrm{HCQ}$, with no significant difference observed among the three treatments (Fig. 2).

$L-H C Q+A R T$ treatment decreases the anti-ds-DNA, ANA and IgG levels. As shown in Fig. 3, the anti-ds-DNA, ANA and IgG levels in the model group were significantly increased compared with the sham group $(\mathrm{P}<0.05)$. However, treatment of LN mice with PDS, H-HCQ and L-HCQ + ART was able to significantly decrease the levels of anti-ds-DNA, ANA and $\operatorname{IgG}(\mathrm{P}<0.05)$. These data indicated that L-HCQ + ART treatment had a similar immunosuppressive effect with that of H-HCQ treatment.

$L-H C Q+A R T$ regulates the KLF15 and $N F-\kappa B$ expression levels. As shown in Fig. 4, the model group exhibited significantly lower expression of KLF15 and higher expression of $\mathrm{NF}-\mathrm{kB}$ at the mRNA and proteins levels, as compared with the sham group $(\mathrm{P}<0.05)$. However, PDS, H-HCQ and $\mathrm{L}-\mathrm{HCQ}+\mathrm{ART}$ treatment significantly increased the expression of KLF15 and decreased the expression of NF- $\mathrm{KB}$ to varying degrees $(\mathrm{P}<0.05)$. The results revealed that $\mathrm{L}-\mathrm{HCQ}+\mathrm{ART}$ in $\mathrm{LN}$ mice was able to reverse the inflammatory response by downregulating NF- $\mathrm{BB}$ and increasing the level of KLF15 expression.

$L-H C Q+A R T$ decreases the serum IFN- $\gamma, T N F-\alpha$ and TGF- $\beta 1$ levels. As shown in Fig. 5, the contents of IFN- $\gamma$, 


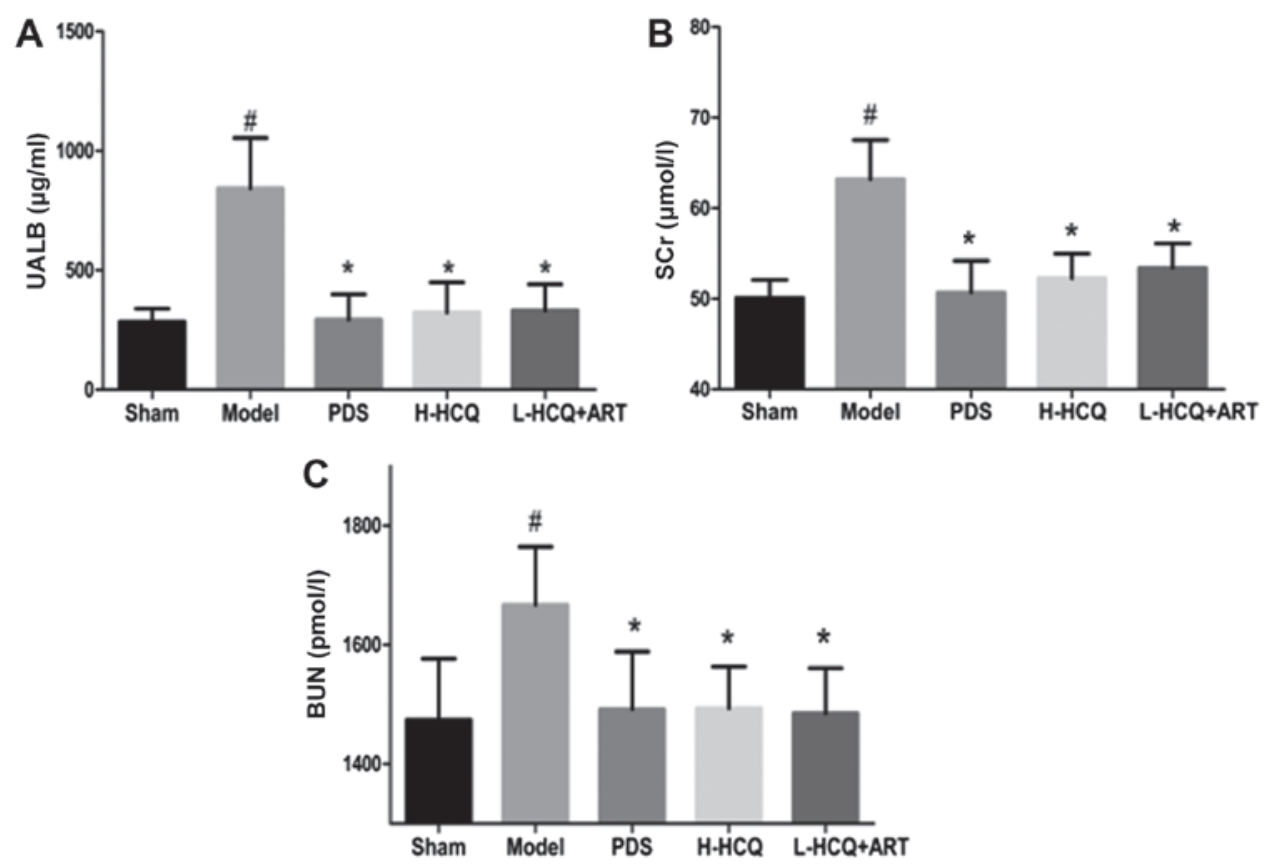

Figure 2. Contents of (A) UALB, (B) SCr and (C) BUN in each group. The values are expressed as the mean \pm standard deviation ( $\mathrm{n}=10$ mice). ${ }^{\text {"P }}<0.01$, vs. the sham group; "P<0.05 vs. the model group. PDS, prednisone; H-HCQ, high-dose hydroxychloroquine; L-HCQ, low-dose hydroxychloroquine; ART, artemisinin; UALB, urine albumin; SCr, serum creatinine; BUN, blood urea nitrogen.
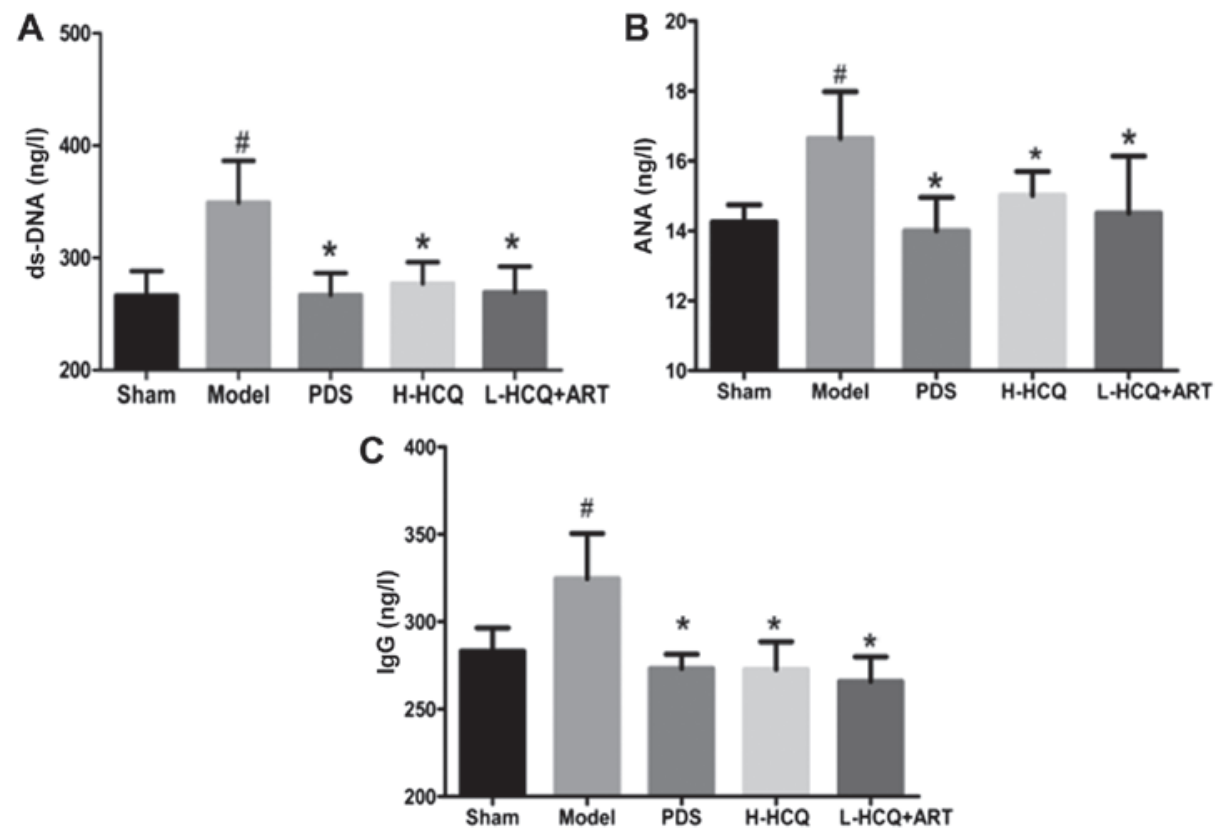

Figure 3. Serum contents of (A) ds-DNA, (B) ANA and (C) IgG in each group, as determined by ELISA. The values are expressed as the mean \pm standard deviation ( $\mathrm{n}=10$ mice). ${ }^{\prime} \mathrm{P}<0.01$, vs. the sham group; ${ }^{\mathrm{P}}<0.05$ vs. the model group. PDS, prednisone; $\mathrm{H}-\mathrm{HCQ}$, high-dose hydroxychloroquine; $\mathrm{L}-\mathrm{HCQ}$, low-dose hydroxychloroquine; ART, artemisinin; ds-DNA, double stranded DNA; ANA, antinuclear antibodies; IgG, immunoglobulin G.

TNF- $\alpha$ and TGF- $\beta 1$ in the serum were markedly increased in the model group compared with the sham group $(\mathrm{P}<0.05)$. However, these alterations were reversed in the three treatment groups, and PDS, H-HCQ and L-HCQ + ART treatments were observed to markedly decrease the levels of IFN- $\gamma$, TNF- $\alpha$ and TGF- $\beta 1$ in the LN mice $(\mathrm{P}<0.05)$. These data indicated that L-HCQ + ART improved the inflammatory status of LN mice, similarly to the treatments with PDS and H-HCQ.
L-HCQ + ART improves the renal and splenic pathomorphology. The results of the renal and splenic histopathology examination by HE staining are shown in Figs. 6 and 7 , respectively. In the model group, severe pathological injury was observed in both the renal and splenic tissues. In the renal tissue, the injury was characterized by glomerulus enlargement, irregular glomerular basement membrane thickening and an increase in the glomerular cell number. In the splenic tissue, injury was characterized by clear cell interstitial 
A

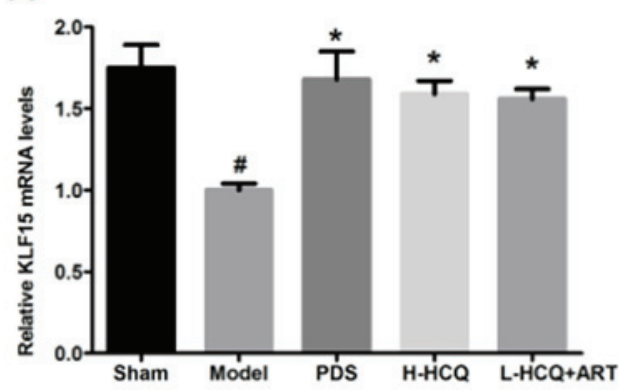

C
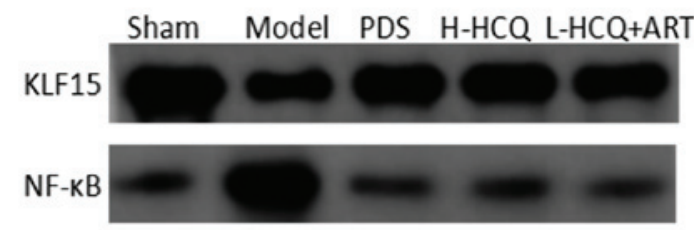

GAPDH
B

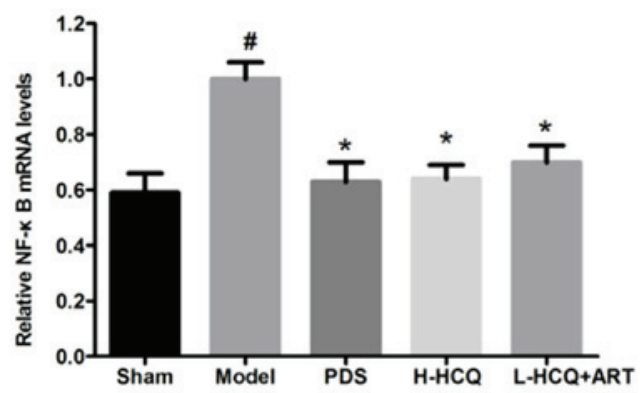

D

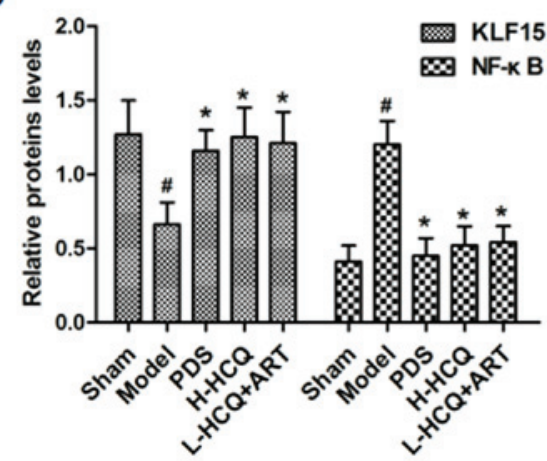

Figure 4. mRNA expression levels of (A) KLF15 and (B) NF- $\mathrm{kB}$ in the kidneys were determined by polymerase chain reaction. (C) Western blots and (D) quantified protein expression levels of KLF15 and NF- $\mathrm{kB}$ in the kidney tissues. The values are expressed as the mean \pm standard deviation (n=10 mice). ${ }^{\text {"P}} \mathrm{P}<0.01$, vs. the sham group; " $\mathrm{P}<0.05$ vs. the model group. PDS, prednisone; H-HCQ, high-dose hydroxychloroquine; L-HCQ, low-dose hydroxychloroquine; ART, artemisinin; KLF15, Kruppel-like factor 15; NF-кB, nuclear factor-кB.

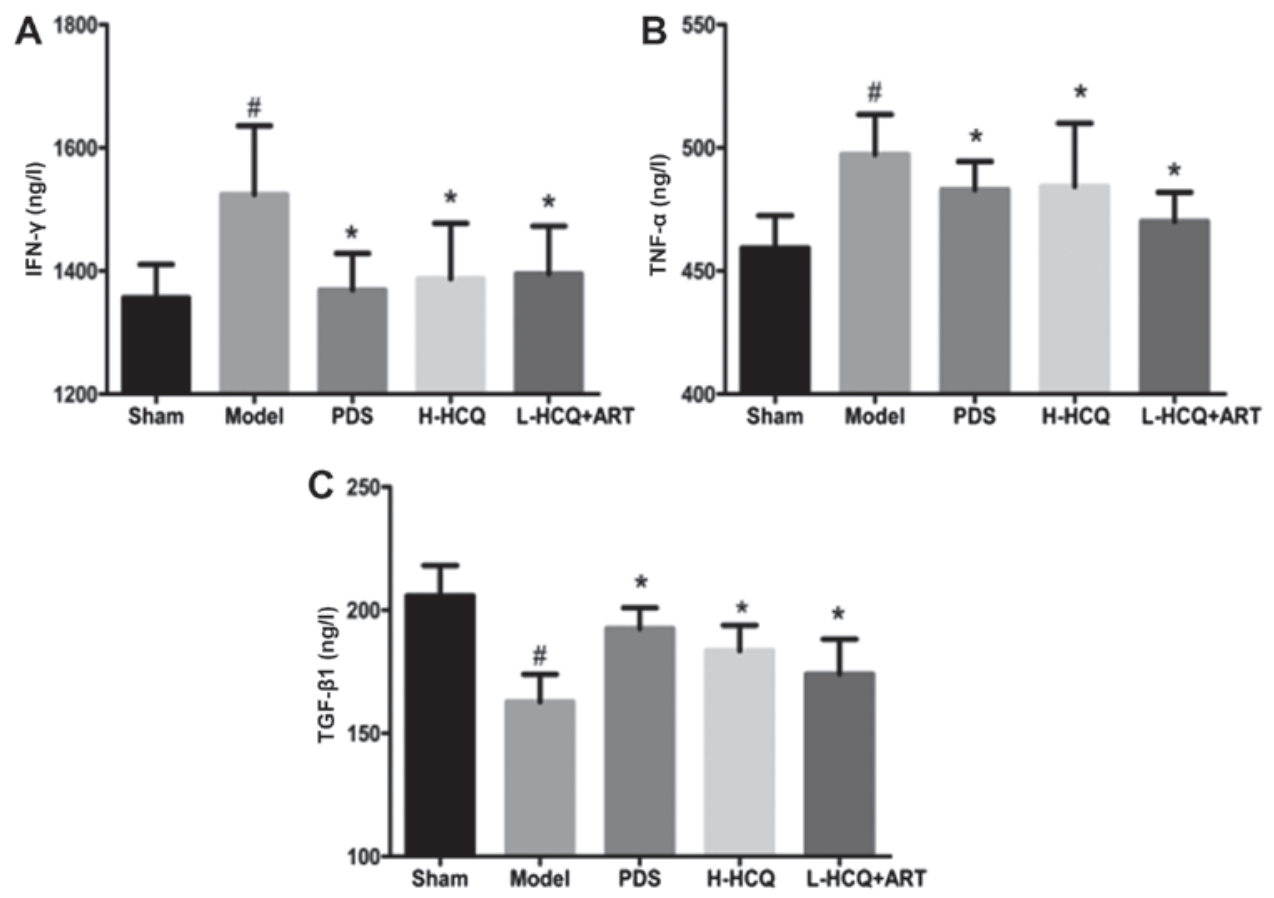

Figure 5. Serum concentrations of (A) IFN- $\gamma$, (B) TNF- $\alpha$ and (C) TGF- $\beta 1$ in each group, as determined by ELISA. The values are expressed as the mean \pm standard deviation $\left(\mathrm{n}=10\right.$ mice). ${ }^{\#} \mathrm{P}<0.01$, vs. the sham group; ${ }^{*} \mathrm{P}<0.05$ vs. the model group. $\mathrm{PDS}$, prednisone; H-HCQ, high-dose hydroxychloroquine; L-HCQ, low-dose hydroxychloroquine; ART, artemisinin; IFN- $\gamma$, interferon $\gamma$; TNF- $\alpha$, tumor necrosis factor- $\alpha$; TGF- $\beta 1$, transforming growth factor $\beta 1$.

edema, splenic corpuscle hyperplasia, periarterial lymphatic sheath thickening and partial splenic artery fibrosis. Notably, these histopathological changes were ameliorated following treatment with L-HCQ + ART, with a similar effect observed upon treatment with H-HCQ or PDS. This suggests that the L-HCQ + ART combination presented a similar effect to that of H-HCQ and PDS treatment, alleviating the pathological renal and splenic damage in $\mathrm{LN}$ mice. 


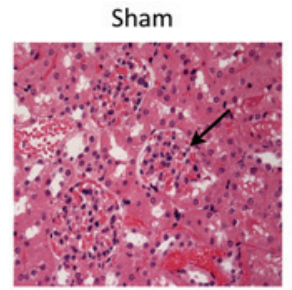

$\mathrm{H}-\mathrm{HCQ}$

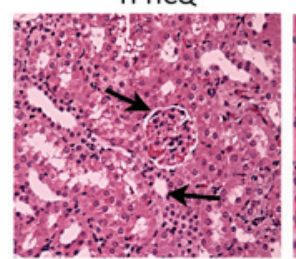

Figure 6. Hematoxylin and eosin staining of the renal tissue in each group (magnification, x400). PDS, prednisone; H-HCQ, high-dose hydroxychloroquine; L-HCQ, low-dose hydroxychloroquine; ART, artemisinin.

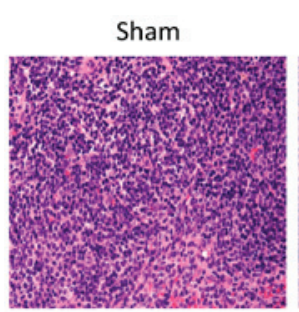

$\mathrm{H}-\mathrm{HCQ}$

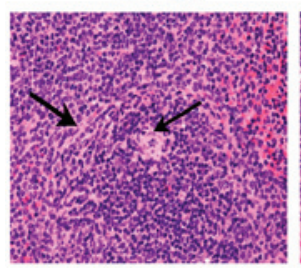

Figure 7. Hematoxylin and eosin staining of the spleen tissue in each group (magnification, x400). PDS, prednisone; H-HCQ, high-dose hydroxychloroquine; L-HCQ, low-dose hydroxychloroquine; ART, artemisinin.

\section{Discussion}

It has been previously reported that $\mathrm{LN}$ is accompanied by renal function failure (19). When LN occurs the normal glomerular filtration function is damaged, ultimately leading to elevated levels of $\mathrm{SCr}$ and BUN, and the formation of proteinuria (20). In addition, $\mathrm{LN}$ is characterized by an increase in ds-DNA and IgG levels, and a decrease in ANA $(21,22)$. LN is initiated by the glomerular deposition of $\mathrm{IgG}$ and complement in the majority of cases (23). ds-DNA is considered to be one of the characteristics of the polyreactive autoantibody pathogenesis of LN. Anti-DNA antibodies exert their pathogenic effects through deposition as immune complexes in the kidney or through the recognition of cross-reactive antigens in the kidney, while in situ deposition of an immune complex (composed of DNA, anti-DNA antibody and IgG) in the renal tissue leads to the activation of the complement system and causes a series of immune injury (24). Tubulointerstitial injury is found frequently in lupus nephritis. Immune complex deposits can occur in the tubular basement membranes (TBMs), it was proved TBM deposits were common in lupus nephritis patients and correlated closely with the clinical disease activity and renal outcome.

In the present study, the results indicated that treatment with PDS, H-HCQ or L-HCQ + ART significantly decreased the levels of UALB, SCr, BUN, ds-DNA, ANA and IgG. Treatment with a low dose of HCQ combined with ART was observed to have a similar effect to that of a high dose of HCQ. Furthermore, HE staining indicated that L-HCQ + ART improved the renal pathologic damage in $\mathrm{LN}$ mice, and weight detection indicated that this combined treatment inhibited the $\mathrm{LN}$-induced weight loss. The aforementioned results suggested that a low dose of HCQ combined with ART was able to improve the $\mathrm{LN}$-induced renal function failure.

Podocyte injury resulting from a loss of differentiation is the hallmark of various glomerular diseases. KLF15 is a key regulator of podocyte differentiation, and a loss of KLF15 increases the susceptibility to kidney injury (25). KLF15 is highly expressed in the normal endothelial and mesangial cells of the kidney (26). NF- $\kappa \mathrm{B}$ is a downstream target gene of KLF15, and KLF15 affects the downstream cascade reaction by regulating the expression of $N F-\kappa B$. A previous study has demonstrated that KLF15 alters the acetylation status of $N F-\kappa B$ and activates $N F-\kappa B$ by direct interaction with P300 (27). In general, the coactivator P300 interacts with $\mathrm{NF}-\kappa \mathrm{B}$ p56 to induce the NF- $\kappa \mathrm{B}$ acetylation-activated inflammatory pathway, while KLF15 interferes with the formation of P300-p56 by competing with P300. Therefore, increasing the expression level of KLF15 can inhibit the activity of $\mathrm{NF}-\kappa \mathrm{B}$, consequently inhibiting the inflammatory response and improving the LN (28). In the present study, KLF15 was significantly decreased and $\mathrm{NF}-\kappa \mathrm{B}$ was markedly increased following allogeneic lymphocyte injection for 4 weeks. By contrast, treatment with PDS, H-HCQ or L-HCQ + ART was able to reverse these alterations. Thus, the current study proved that L-HCQ combined with ART may regulate the KLF15-NF- $\kappa \mathrm{B}$ signaling pathway.

$\mathrm{NF}-\kappa \mathrm{B}$ belongs to a family of inducible transcription factors. Accumulating evidence demonstrates that the transcription factor NF- $\kappa \mathrm{B}$ serves a crucial role in regulating the expression of numerous pro-inflammatory cytokines during the immune response (1). TNF- $\alpha$ activates the $N F-\kappa B$ signaling pathway in order to amplify the inflammatory response and increases the duration of chronic inflammation (5). In addition, Yazici et al reported that IFN- $\gamma$ may have a role in the pathogenesis and progression of LN (29). T-cell cytokines, including IFN- $\gamma$, have also been detected in nephritic kidneys (30). Furthermore, TGF- $\beta 1$, as an important cytokine, has been demonstrated to promote extracellular matrix synthesis and secretion, and lead to mesangial cell proliferation (31). Therefore, the measurement of inflammatory cytokine IFN- $\gamma$, TNF- $\alpha$ and TGF- $\beta 1$ levels is of great significance for predicting the development of LN. In the current study, PDS, H-HCQ or L-HCQ + ART was observed to decrease significantly the levels of IFN- $\gamma$, TNF- $\alpha$ and TGF- $\beta 1$, while the L-HCQ + ART combined treatment and H-HCQ alone had a similar anti-inflammatory effect. Additionally, HE staining of tissue from the spleen, the main immune organ, indicated that L-HCQ + ART improved the spleen pathologic damage in LN mice. These results confirmed that anti-inflammatory effect is one of the mechanisms underlying the action of these treatments. Furthermore, it is 
suggested that improvements in the immunologic response and anti-inflammatory ability are the dominant mechanisms involved in the attenuation of LN following L-HCQ + ART combined treatment.

In conclusion, the present study demonstrated that the combination of a low dose of HCQ and ART presented a similar immunosuppressive effect as that of the PDS and H-HCQ treatments. The potential mechanisms underlying the effect of L-HCQ + ART combined treatment may be through regulation of the expression levels of cytokines, KLF15 and $\mathrm{NF}-\kappa \mathrm{B}$. The use of a low dose of HCQ may help reduce the side effects of H-HCQ, which may provide a novel method for the treatment of LN.

\section{Acknowledgements}

The present study was supported by the YangFan Innovative and Entrepreneurial Research Team Project (grant no. 2014YT02S008), the China Postdoctoral Science Foundation (grant no. 2015M572294) and the Guangdong Provincial Science and Technology Department Project (grant no. 2014B050502013).

\section{References}

1. Bhatt D and Ghosh S: Regulation of the NF- $\mathrm{BB}-$ mediated transcription of inflammatory genes. Front Immuno 5: 71, 2014.

2. Appel GB, Contreras G, Dooley MA, Ginzler EM, Isenberg D, Jayne D, Li LS, Mysler E, Sánchez-Guerrero J, Solomons N, et al: Mycophenolate mofetil versus cyclophosphamide for induction treatment of lupus nephritis. J Am Soc Nephrol 20: 1103-1112, 2009.

3. Ruiz-Irastorza G, Danza A, Perales I, Villar I, Garcia M, Delgado S and Khamashta M: Prednisone in lupus nephritis: How much is enough? Autoimmun Rev 13: 206-214, 2014.

4. Illei GG, Austin HA, Crane M, Collins L, Gourley MF, Yarboro CH, Vaughan EM, Kuroiwa T, Danning CL, et al: Combination therapy with pulse cyclophosphamide plus pulse methylprednisolone improves long-term renal outcome without adding toxicity in patients with lupus nephritis. Ann Intern Med 135: 248-257, 2001.

5. Kawasaki H, Onuki R, Suyama E and Taira K: Identification of genes that function in the TNF-alpha-mediated apoptotic pathway using randomized hybrid ribozyme libraries. Nat Biotechnol 20: 376-380, 2002

6. Zheng ZH, Zhang LJ, Liu WX, Lei YS, Xing GL, Zhang JJ, Quan SX, Liu D, Hu DS, Li LL and Liu ZS: Predictors of survival in Chinese patients with lupus nephritis. Lupus 21: 1049-1056, 2012.

7. Pons-Estel GJ, Alarcón GS, McGwin G jr, Danila MI, Zhang J, Bastian HM, Reveille JD and Vilá LM; Lumina Study Group: Protective effect of hydroxychloroquine on renal damage in patients with lupus nephritis: LXV, data from a multiethnic US cohort. Arthritis Rheum 61: 830-839, 2009.

8. Lee SJ, Silverman E and Bargman JM: The role of antimalarial agents in the treatment of SLE and lupus nephritis. Nat Rey Nephrol 7: 718-729, 2011.

9. Wallace DJ, Gudsoorkar VS, Weisman MH and Venuturupalli SR: New insights into mechanisms of therapeutic effects of antimalarial agents in SLE. Nat Rev Rheumatol 8: 522-533, 2012.

10. Costedoat-Chalumeau N, Dunogué B, Leroux G, Morel N, Jallouli M, Le Guern V, Piette JC, Brézin AP, Melles RB and Marmor MF: A critical review of the effects of hydroxychloroquine and chloroquine on the eye. Clin Rev Allergy Immunol 49: 317-326, 2015.

11. Bhavsar KV, Mukkamala LK and Freund KB: Multimodal imaging in a severe case of hydroxychloroquine toxicity. Ophthalmic Surg Lasers Imaging Retina 46: 377-379, 2015.

12. Ding HJ, Denniston AK, Rao VK and Gordon C: Hydroxychloroquine-related retinal toxicity. Rheumatology (Oxford) 55: 957-967, 2016.
13. Abdel Galil SM: Hydroxychloroquine-induced toxic hepatitis in a patient with systemic lupus erythematosus: A case report. Lupus 24: 638-640, 2015.

14. Wu Y, He S, Bai B, Zhang L, Xue L, Lin Z, Yang X, Zhu F, He P, Tang $W$ and Zuo J: Therapeutic effects of the artemisinin analog SM934 on lupus-prone MRL/lpr mice via inhibition of TLR-triggered B-cell activation and plasma cell formation. Cell Mol Immunol 13: 379-390, 2016.

15. Wu XL, Zhang WG, Shi XM, An P, Sun WS, Qiao CL and Wang Z: Effect of artemisinin combined with glucocorticoid on the expressions of glucocorticoid receptor $\alpha$ mRNA, glucocorticoid receptor $\beta$ mRNA and P300/CBP protein in lupus nephritis mice. Chin J Integr Med 17: 277-282, 2011.

16. The People's Republic of China of Laboratory Animals-Guideline of welfare and ethics. Standardization Administration of China, 2016.

17. Wen ZK, Xu W, Xu L, Cao QH, Wang Y, Chu YW and Xiong SD: DNA hypomethylation is crucial for apoptotic DNA to induce systemic lupus erythematosus-like autoimmune disease in SLE-non-susceptible mice. Rheumatology (Oxford) 46: 1796-1803, 2007.

18. Livak KJ and Schmittgen TD: Analysis of relative gene expression data using real-time quantitative PCR and the 2(-Delta Delta C(T)) method. Methods 25: 402-408, 2001.

19. Shaharir SS, Ghafor AA, Said MM and Kong NC: A descriptive study of the factors associated with damage in Malaysian patients with lupus nephritis. Lupus 23: 436-442, 2014.

20. Zhang ZM, Zhao L, Zhang X L and Wang XF: Correlation analysis between urinary $\mathrm{T}$ lymphocyte subsets and lupus nephritis disease activity. Int J Clin Exp Med 10: 6061-6070, 2017.

21. Bertsias GK, Tektonidou M, Amoura Z, Aringer M, Bajema I, Berden JH, Boletis J, Cervera R, Dörner T, Doria A, et al: Joint European league against rheumatism and European renal association-European dialysis and transplant association (EULAR/ERA-EDTA) recommendations for the management of adult and paediatric lupus nephritis. Ann Rheum Dis 71: 1771-1782, 2012

22. Imran TF, Yick F, Verma S, Estiverne C, Ogbonnaya-Odor C, Thiruvarudsothy S, Reddi AS and Kothari N: Lupus nephritis: An update. Clin Exp Nephrol 20: 1-13, 2016.

23. Tucci M, Stucci S, Strippoli S and Silvestris F: Cytokine overproduction, T-cell activation and defective T-regulatory functions promote nephritis in systemic lupus erythematosus. Bio Med Res Int 2010: 457146, 2010.

24. Deshmukh US, Bagavant $\mathrm{H}$ and Fu SM: Role of anti-DNA antibodies in the pathogenesis of lupus nephritis. Autoimmun Rev 5: 414-418, 2006.

25. Mallipattu SK, Liu R, Zheng F, Narla G, Ma'ayan A, Dikman S, Jain MK, Saleem M, D'Agati V, Klotman P, et al: Kruppel-like factor 15 (KLF15) is a key regulator of podocyte differentiation. J Biol Chem 287: 19122-19135, 2012.

26. Hong Q, Li C, Xie Y, Lv Y, Liu X, Shi S, Ding R, Zhang X, Zhang L, Liu S and Chen X: Kruppel-like factor-15 inhibits the proliferation of mesangial cells. Cell Physiol Biochem 29: 893-904, 2012.

27. Lu Y, Zhang L, Liao X, Sangwung P, Prosdocimo DA, Zhou G, Votruba AR, Brian L, Han YJ, Gao H, et al: Kruppel-like factor 15 is critical for vascular inflammation. J Clini Invest 123: 4232-4241, 2013,

28. Jain MK, Sangwung $P$ and Hamik A: Regulation of an inflammatory disease. Arterioscler Thromb Vasc Biol 34: 499-508, 2014.

29. Yazici MU, Orhan D, Kale G, Besbas N and Ozen S: Studying IFN-gamma, IL-17 and FOXP3 in pediatric lupus nephritis. Pediatr Nephrol 29: 853-862, 2014.

30. Davidson A: What is damaging the kidney in lupus nephritis? Nat Rev Rheumatol 12: 143-153, 2016.

31. Yang L, Sun X, Zhan Y, Liu H, Wen Y, Mao H, Dong XI and Li P: Yi Qi Qing Re Gao-containing serum inhibits lipopolysaccharide-induced rat mesangial cell proliferation by suppressing the Wnt pathway and TGF- $\beta 1$ expression. Exp Ther Med 11: 1410-1416, 2016.

This work is licensed under a Creative Commons Attribution-NonCommercial-NoDerivatives 4.0 International (CC BY-NC-ND 4.0) License. 